\title{
A bicha e o macho: poder e resistência nas músicas de Linn da Quebrada
}

\author{
La cola y el macho: poder y resistência em lãs canciones de Linn da \\ Quebrada
}

\section{The fag and the male: Power and resistance in Linn da Quebrada's songs}

\author{
João Vitor Xavier dos Santos ${ }^{1}$ \\ Adélli Bortolon Bazza ${ }^{2}$
}

\begin{abstract}
Resumo
Na última década, observou-se um aumento das discussões sobre gênero, bem como da visibilidade de sujeitos pertencentes à comunidade LGBTQ+. Além de se diferenciar da comunidade externa a ela, a dita heterossexual, a própria sigla demonstra que internamente há vários grupos e, portanto várias subjetividades.Desse modo, buscamos investigar o jogo de forças estabelecido internamente à comunidade LGBTQ+e a sua consequente relação com a circulação/validação de subjetividades.No esteio de uma análise discursiva que mobiliza noções foucaultianas, são mobilizados neste trabalho conceitos comosubjetividade, poder e resistência. A série enunciativa mobilizada é composta por músicas da cantora Lin da Quebrada, em seu álbum 'Pajubá', lançado em 2017. As análises indicaram que o discurso construído nas músicas estabelece uma resistência ao padrão do gay com perfil masculinizado, o macho, em prol da valorização da subjetividade do gayfeminio, a bicha.
\end{abstract}

Palavras-chave:ComunidadeLGBTQ+, Discurso, Heteronormatividade; Resistência, Subjetividade.

\section{Resumen}

En la última década, se observó un aumento de las discusiones sobre género, así como de la visibilidad de sujetos pertenecientes a la comunidad LGBTQ+. Además de diferenciarse de la comunidad externa a ella, la dicha heterosexual, la propia sigla demuestra que internamente hay varios grupos $y$, por lo tanto, varias subjetividades. De ese modo, buscamos investigar el juego de fuerzas establecido internamente a la comunidad LGBTQ+ y su consecuente relación con la circulación / validación de subjetividades. En el seno de un análisis discursivo que moviliza nociones foucaultianas, se movilizan en este trabajo conceptos como subjetividad, poder y resistencia. La serie enunciativa movilizada está compuesta por canciones de la cantante Lin da Quebrada, en su álbum 'Pajubá', lanzado en 2017. Los análisis indicaron que el discurso construido en las canciones establece una resistencia al patrón del gay con perfil masculino, el macho, de la valorización de la subjetividad del gay femenino, la cola.

Palabras claves: Comunidad LGBTQ+; Discurso; Heteronormatividad; Resistencia, Subjetividad.

\footnotetext{
${ }^{1}$ Graduando em Letras; Universidade Estadual de Maringá; Maringá, Paraná, Brasil; joao_jvxs@ live.com.

${ }^{2}$ Doutora em Letras; Universidade Estadual de Maringá; Maringá, Paraná, Brasil; adellibazza@ hotmail.com.
} 


\begin{abstract}
In the last decade, discussions on gender issues have increased, together with the visibility of subjects belonging to the LGBTQ+ community. The acronym itself differs that group from the straight, showing that there are several groups and therefore multiple subjectivities inside it. Thereby, we investigate the forces established within the LGBTQ+ community and their consequent relationship to the movement/validation of subjectivities. In the core of a discursive analysis that mobilizes Foucauldian notions, some concepts as subjectivity, power and resistance are mobilized in this work. The enunciative series mobilized in the present work is composed of songs of the singer Linn da Quebrada, in her album 'Pajubá', launched in 2017. The analyses indicated that the speech constructed in those songs establishes a resistance to the standard of the gay behaviorwith more evident male profile, the male, favoring the valuation of the subjectivity of amore feminine gay, the fag.
\end{abstract}

Keywords: Discourse; Heteronormativity; LGBTQ+ Community;Resistance; Subjectivity.

\title{
1. Introdução
}

Neste artigo, propõe-se uma discussão sobre as relações de poder presentes no meio LGBTQ+ materializadas nas músicas da cantora e mulher trans Linn da Quebrada, em seu álbum Pajubá, lançado em 2017. Linn faz parte de uma gama de artistas LGBTQ+ que inclui aqueles que vieram antes dela como: Freddie Mercury, David Bowie, Renato Russo, Ney Matogrosso, Cazuza, Ana Carolina, Daniela Mercury, entre outros. Nesse sentido, atualmente vive-se uma onda crescente da arte vinda dessa comunidade, em especial na música com nomes como PablloVittar (que rompeu as fronteiras da comunidade indo além desta) e outros também como Liniker, Caio Prado, RuPaul, Gloria Grove, que ainda têm a circulação de suas músicas mais concentradas internamente à comunidade LGBTQ+.

A seleção por esse grupo social se justifica pelo fato de que se trata de um movimento que vem crescendo tanto em número quanto em representatividade social e que apresenta muitos gestos em favor da quebra de antigos padrões criados em uma sociedade com um cerne heteronormativo e machista. Esses valores, posto que arraigados por toda uma teia social, refletem inclusive no meio LGBTQ+, no qual há uma valorização social implícita e muitas vezes explícita de certos padrões construídos pela heteronormativização. Uma orientação como essa contribui para a criação de um ambiente em que o homem homossexual, mesmo entre seus pares, sente-se mais aceito quando se comporta como "macho"; e aquele que apresenta jeito ou características consideradas socialmente como femininas é marginalizado.

Nesse contexto, o relevo dessas músicas e nosso consequente interesse por elas se dá pelo fato de representarem movimentos culturais e sociais internos ao movimento LGBTQ+ que buscam legitimar o lugar do homossexual afeminado, da travesti. Sendo assim, dão voz a 
esses que, até hoje, vêm sendo marginalizados. As análises decorrem de uma orientação discursiva, pautada nos pressupostos teóricos lançados por Michel Foucault, notadamente: discurso, saber, posição sujeito, poder e resistência. Uma reflexão, assim proposta, foca na resistência exercida pelo discurso constituído nas músicas analisadas como uma maneira de questionar e romper com certa verdade sobre o homem gay e suas práticas.

\section{LGTBQ+: a constituição de um sujeito}

A homossexualidade já era registrada no Brasil desde as missões jesuítas, em que se relatavam casos de desvios sexuais entre os índios. Aparecem ainda registros de duas visitas inquisitoriais feitas em Pernambuco e na Bahia nas quais boa parte dos casos relatados eram de sodomia. Também há registros de que, no período imperial, no Rio de Janeiro já existiam locais frequentados por homossexuais além de espaços para o sexo homossexual (JÚNIOR, 2008).

A despeito desses relatos, foi apenas no final da década de 1960 que se configurou um movimento gay no Brasil. Tal emergência foi influenciada pelo movimento gay norte americano e pelo atentado de Stonewall. Este se tratava de um bar frequentado por gays, lésbicas e travestis. Em 28 de junho de 1969, uma invasão policial com a pretensão de fechálo despertou seus frequentadores que, cansados do abuso policial, enfrentam-nos, armados com pedras e garrafas e aos gritos de "Sou bicha e me orgulho disso". O confronto prolongouse por cinco dias, atraindo a atenção da imprensa e despertando a comunidade LGBT de várias partes do mundo em um movimento de resistência (JÚNIOR, 2008). Foi nesse momento também que surgiram, na imprensa brasileira, as primeiras manifestações não negativas tratando da comunidade LGBT, com a criação do Lampião da Esquina, jornal que ainda durante a ditadura, deu voz à ainda inexpressiva comunidade LGBT, sendo resistência ao forte moralismo do período.

Como parte do processo de formação de uma comunidade variada, tem se registrado o surgimento do "Movimento Homossexual" (MH), como entende Regina Facchini (2003, p.84):

como o conjunto das associações e entidades, mais ou menos institucionalizadas, constituídas com o objetivo de defender e garantir direitos relacionados a livre orientação sexual e/ou reunir, com finalidades não exclusivamente, mas necessariamente políticas, indivíduos que se reconheçam a partir de qualquer uma das identidades sexuais tomadas como sujeito desse movimento. 
A autora divide a trajetória do $\mathrm{MH}$ em três momentos, o primeiro chamado por ela de "Primeira Onda" surge com a fundação do grupo SOMOS, de São Paulo, em 1978. Desde o primeiro momento, percebe-se a fragmentação do MH,que surge a partir de um grupo formado apenas por homens, como um grupo de afirmação homossexual e apenas posteriormente recebeu novos integrantes, entre eles mulheres que ainda representavam uma minoria no grupo. Como reflete Astor Vieira Junior (2008, p. 185):

Apesar de as mulheres estarem incluídas no universo homossexual, elas são postas à margem devido à ignorância que, muitas vezes, permeia o grupo e a sociedade. Curiosamente, apenas gay está posto como identificação a homossexual e homossexualidade. Subliminarmente, isso quer dizer que a mulher lésbica está fora dessa disputa política, pois esse tipo de disputa é um retrato da atividade e não-passividade; é coisa para macho.

MacRae (1990), ao analisar o grupo nesse momento, percebe uma marginalização feita pelos militantes aos homossexuais frequentadores do "gueto", uma forte distinção entre aqueles que pertenciam ao grupo e aos que estavam de fora. Disso, decorre o desejo da criação de uma comunidade de iguais dentro do grupo, o que pó um lado atua unindo as pessoas e por outro aponta para homogeneização de seus integrantes. Dessa forma,atua construindo um modelo de identidade homossexual. O autor ainda traz à tona questões como a bissexualidade, que, para o grupo, era criticada como uma evasiva para não se assumir uma homossexualidade, embora a pratica bissexual, em alguns momentos, fosse vangloriada como quebra de todas as regras (FACCHINI, 2003).

Em 1980, mesmo ano do primeiro Encontro de Grupos Homossexuais Organizados (EGHO), aconteceram as primeiras fragmentações no grupo SOMOS, que se dividiu em: o SOMOS, o Grupo Lésbico-feminista e o Grupo de Ação Homossexualista (posteriormente chamado Outra Coisa). A década de 80 trouxera fragmentação e o declínio do grupo SOMOS, assim como do Movimento Homossexual. Questões político-sociais e o surgimento e epidemia do HIV influenciaram internamente o movimento.

Com a segunda onda o $\mathrm{MH}$ ganhou força, contudo encampou outros objetivos. O grupo deixou de ter como norte a criação e a reflexão sobre uma identidade homossexual baseada no eu, voltando-se para questões sociais que afetavam a comunidade LGBT em geral. Discutia-se a "despatologização" da homossexualidade, o casamento homossexual e a reinvindicação de uma representação positiva da homossexualidade na mídia, a qual desde o auge do vírus HIV disseminava uma imagem negativa da comunidade LGBT. 
Num dado sentido, em Desire: AIDS, Pornography, andthe Media[1988], Simon Watney identificou a construção contemporânea da 'pessoa poluidora' com a pessoa portadora de AIDS. Não só a doença é representada como a 'doença gay', mas na reação histérica e homofóbica da mídia à doença registra-se a construção tática de uma continuidade entre o status poluído do homossexual, em virtude da violação de fronteiras que é o homossexualismo, e a doença como modalidade específica de poluição homossexual (BUTLER, 1990, p. 189)

No início da década de 1990 iniciou-se a terceira onda, a qual trouxe um aumento do número de grupos exclusivamente lésbicos, a participação de militantes no Partido dos Trabalhadores.Além da fragmentação interna do MHB por questões raciais, políticas e de gênero Peter Fry (1982)discute ainda divisões específicas entre os homens homossexuais. Baseado em seus estudos realizados na periferia de Belém, o antropólogo apresenta a taxonomia Homens e Bicha. Nesse sistema, os machos (termo usado pelo autor referindo-se ao sexo fisiológico) dividem-se em dois grupos: as Bichas e os Homens que se diferenciam em seu comportamento sexual e social. À medida que o Homem apresentaria um comportamento "masculino" a Bicha apresentaria um comportamento prototipicamente associado ao gênero feminino. Ainda segundo Fry (1982, p. 90), "a relação entre homens e bichas é análoga à que se estabelece entre homens e mulheres no mesmo contexto social, onde os papeis de gênero masculino e feminino são altamente segregados e hierarquizados". O autor salienta, porém, que esse modelo classificatório não se restringe à periferia de Belém, "ela aparece em toda a sociedade brasileira, coexistindo, e às vezes competindo, com outros sistemas" sendo, todavia, mais comum em regiões do Norte e Nordeste e no interior do país.

Isso posto, a fragmentação do MHB, que aparece desde o início do movimento, se dá devido à heterogeneidade da comunidade, hoje denominadaLGBTQ+, gerando assim grupos variados em suas especificidades e que vão contra ao normativismo descendente da heteronormatividade social. Faz-se possível perceber, na história da homossexualidade no Brasil, a influência de poderes machistas que criam uma hierarquia social interna à comunidade e ainda, mais especificamente, dentro do grupo homens homossexuais.

\section{As subjetividades e as lutas de poder}

Tratar das disputas por espaço, sejam elas externas ou internas ao movimento LGBTI+, implica pensar sobre como as pessoas se constituem em sujeitos no discurso e como constituem subjetividades nas quais podem se reconhecer. É a partir da identificação com determinadas práticas que o sujeito se descreve como parte de um grupo ou movimento e 
como distinto de outro. Esse processo, apesar de abarcar uma singularidade, é construído em um tecido social em que atuam as forças da história, da memória e as relações de poder.

De acordo com Foucault (2013b, p. 63),"na raiz daquilo que nós conhecemos e daquilo que nós somos- não existem a verdade e o ser, mas a exterioridade do acidente".Isso quer dizer que, quando alguémé categorizado como gay, bicha ou travesti não está se falando de algo que seja intrínseco ao sujeito, mas de formas de classificá-lo e essas formas são resultados de uma construção discursiva que, além de constituir objetos, valora-os positiva ou negativamente.

Pensada a partir de uma visada discursiva, a subjetividade deixa de ser algo intrínseco a um sujeito soberano de si e que se desenvolveria linearmente.

A história, genealogicamente dirigida, não tem por fim reeencontrar as raízes de nossa identidade, mas, ao contrário, se obstinar em dissipá-la; ela não pretende demarcar o território único de onde viemos, essa primeira pátria à qual os metafísicos prometem que retornaremos; ela pretende fazer aparecer todas as descontinuidades que nos atravessam. (FOUCAULT, 2013b, p. 8283)

Genealogicamente, não existe uma origem da homossexualidade e um desenvolvimento linear das subjetividades. A produção das subjetividades é pautada por rupturas e ainda assim, descontínua. Isso explica porque dentro um mesmo movimento haja tantas subdivisões e tantas subjetividades concomitantemente: os atravessamentos são diversos, inclusive os de ordem heteronormativa.

A consideração da heterossexualidade como um padrão leva à coerção para que os sujeitos se encaixem e coloca de um lado os héteros e de outro os homos. Estes sujeitados ao exercício de poder daqueles. Contudo, conforme Foucault (2013c, p. 138),“Onde há poder, ele se exerce. Ninguém é, propriamente falando, seu titular; e, no entanto, ele sempre se exerce em determinada direção, com uns de um lado e outros do outro; não se sabe ao certo quem o detém; mas se sabe quem não o possui." Isso implica entender que ainda que haja uma coerção para enquadre no padrão heterossexual, existe a possibilidade de resistir a ele, mesmo quando ele se manifesta internamente à comunidade LGBTQ+.

A compreensão foucaultiana do poder distingue-se de uma visão muito difundida para a qual o poder seria centralizado por alguém ou por algumas instituições e que ele teria uma natureza repressiva e negativa. Para Foucault (2013d, p. 239), entretanto “O poder, longe de 
impedir o saber, o produz.’'É por meio do poder que se constrói e se faz circular o saber sobre a sexualidade em geral, sobre a homossexualidade e suas formas de vivência.

Ainda que haja uma força de coerção por um padrão sexual na sociedade como um todo e que esse padrão se reproduza internamente ao movimento (em tese, uma resistência) é possível questioná-lo, resistir a ele e deslocá-lo.

O poder deve ser analisado como algo que circula, ou melhor, como algo que só funciona em cadeia. Nunca está localizado aqui ou ali, nunca está nas mãos de alguns, nunca é apropriado como uma riqueza ou bem. O poder funciona e se exerce em rede. Nas suas malhas, os indivíduos não só circulam, mas estão sempre em posição de exercer o poder e de sofrer sua ação; nunca são o alvo inerte ou consentido do poder, são sempre centros de transmissão. Em outros termos, o poder não se aplica aos indivíduos, passa por eles. (FOUCAULT, 2013a, p. 284)

Sendo assim, tanto os indivíduos vistos como maioria ou dominantes e aqueles vistos como minoria ou dominados podem mover-se dentro das redes de poder, deslocar seu posicionamento e sua subjetividade. É possível resistir segundo estratégias precisas.Desse modo, propõe-se observar poderes e resistências internas à comunidade LGBTQ+ manifestados no discurso materializado em músicas da cantora Linn da Quebrada.

\section{Linn da Quebrada: a bicha e o macho}

O recorte das músicas da cantora da Quebrada, do álbum Pajubá se deve ao fato de que o álbum inteiro é composto por diversas músicas que representam o desejo de ocupar o seu lugar e reivindicar a voz de uma comunidade marginalizada inclusive dentro da própria sociedade LGBTQ+. Fazem parte da série enunciativa mobilizada músicas que representam de maneira mais incisiva as relações, os desejos e a voz do homossexual afeminado, em resposta ao discurso machista e dominante do homossexual masculino do macho. A saber: A lenda, Transudo, Bixa Travesti, Enviadescer, Talento, Coytada, Prostituto.

Linn canta sobre as relações hierárquicas do masculino e do feminino vindas da heteronormatividade que se dão dentro da comunidade LGBTQ+. No trecho da música $A$ lenda fica clara a posição na qual é colocada o homem homossexual afeminado, chamado aqui de "bicha". Ele é inferiorizado e visto dentro da comunidade em questão como hierarquicamente menor que o homem homossexual que se encaixa nos padrões de gênero construídos pela sociedade heteronormativa. 
Essa bicha é molotov, o bonde das rejeitada

Eu tô bonita? (tá engraçada)

Eu não tô bonita? (tá engraçada)

Me arrumei tanto pra ser aplaudida mas até agora só deram risada

Porque "uma podre maçã deixa as outras contaminada"

(A lenda, Linn da Quebrada)

O trecho apresentado traz um ponto importante para a discussão sobre a posição do sujeito afeminado dentro da comunidade LGBTI+. Logo no primeiro verso, a expressão "o bonde das rejeitada" marca essa posição do sujeito que deveria fazer parte dessa comunidade, a qual supostamente teria em sua essência a participação de uma parcela da sociedade que é marginalizada por sua sexualidade, identidade e cultura. Contudo, observa-se que ela não cumpre com seu suposto objetivo de romper com as regras da comunidade heteronormativa e criar suas próprias regras, mas sim as reproduz e por isso marginaliza os sujeitos afeminados. Entre eles é possível citar a própria Linn, em uma posição de transsexualidade, e também como exemplos de homens cisgêneros, que são homossexuais e afeminados os cantores Johnny Hooker, Rico Dalasam, o cantor e ator sul-africano Troye Sivan, entre outros. Dessa forma os que se apresentam nessa posição de afeminados são rejeitados primeiro pela sociedade heteronormativa e segundo dentro da comunidade LGBTQ+.

Ainda nesse trecho, observa-se um importante questionamento sobre o ser afeminado que e a representatividade desse sujeito tanto na comunidade LGBTQ+, quanto na sociedade heteronormativa como um todo.Em "Eu tô bonita? (ta engraçada)/Eu não tô bonita? (tá engraçada)/Me arrumei tanto pra ser aplaudida mas até agora só deram risada" é posto em questão a representação do homossexual em especial o afeminado, como cômico, entra aqui a memória de personagens icônicos como: Vera Verão, Alfredinho vivido por Lúcio Mauro Filho no programa Zorra Total, o mordomo Crô interpretado por Marcelo Serrado, personagem que surgiu na novela Fina Estampa e devido ao sucesso de sua comicidade ganhou mais dois filmes. Esses são apenas alguns dos exemplos que ilustram a performatividade cômica que é posta sobre o homossexual afeminado.

À vista dessa verdade da hierarquia dos gêneros e da superioridade do masculino, a qual a cantora apresenta e mostra como parte constituinte das relações dentro da comunidade LGBTQ+, surge o movimento de resistência que pretende romper com essa verdade. As músicas do álbum Pajubá representam essa força de resistência.

Tá pagando de transudo

Se achando o maior vilão 
Quer enganar que pega todas

Que vive no luxo, só na ostentação

(...)

Cê podia ter vários pinto

Um pinto gigante

Que bate na testa

(..)

Tenho pena de você

Com o pau apontado pra própria cabeça

Refém de sua frágil masculinidade

Se eu quiser, eu vou sentar

Se tu pedir, eu vou sentar

Mas vou sentar até eu cansar!

(Transudo, Linn da Quebrada)

Um movimento que marca a resistência e tentativa de transgressão na obra de Linn é a quebra do falocentrismo ou a desvalorização do masculino. Esse que até então vinha pelo movimento hierárquico da heteronormatividade sendo posto em posição superior, sofre o enfrentamento do sujeito homossexual afeminado, que questiona essas posições do sujeito construídas.Os trechos apresentados da música Transudo mostram bem o enfrentamento mencionado. Logo no início é dito “Tá pagando de transudo/ Se achando maior vilão/ Quer enganar que pega todas". Aqui, questiona-se a ideia criada do homem "pegador" ou "garanhão" e também a ideia de uma masculinidade baseada nessa concepção de homem "transudo". Mais além é questionada também a ligação de poder ao falo: "Cê podia ter vários pinto/ Um pinto gigante/ Que bate na testa". Nesse trecho, a cantora marca esse poder relacionada ao falo, para logo depois romper com essa ideia, apresentar uma equação onde falo é diferente de poder. Essa quebra fica clara em: "Tenho pena de você/ Com o pau apontado pra própria cabeça/ Refém de sua frágil masculinidade" aqui o modelo antes visto como sinônimo de poder torna-se sinal de fragilidade.

A desvalorização da masculinidade aparece também em outras músicas, como em Bixa Travesti. Nessa o enfrentamento à masculinidade como representada na concepção hierárquica é ainda mais forte. Fica evidente o desejo de romper com esse "reinado" do masculino: "Pode ir saindo com o pau entre as pernas/ Acabou o seu império" o falo aqui novamente perde seu lugar de poder "Tô vendo de camarote o fim do seu reinado/ Rindo muito da sua cara de cãozinho abandonado".Marca-se a perda do poder do macho quando diz: “Quando tiver indo embora, não esquece!, deixa seu pau em cima da mesa/ Vai!”. Como resultado da reformulação das relações de poder a bicha afeminada assume um lugar de visibilidade e de valorização nesse sistema. 
Ei, psiu, você aí, macho discreto

Chega mais, cola aqui

Vamo bater um papo reto

Que eu não tô interessada no seu grande pau ereto

Eu gosto mesmo é das bixas, das que são afeminada

Das que mostram muita pele, rebolam, saem maquiada

Eu vou falar mais devagar pra ver se consegue entender

Se tu quiser ficar comigo, boy (ha-ha-ha)

Vai ter que enviadescer

Mas não tem nada a ver com gostar de rola ou não

Pode vir, cola junto as transviadas, sapatão

Que eu não tô interessada no seu grande pau ereto

Eu gosto mesmo é das bixa, das que são afeminada

Das que mostram muita pele, rebolam, saem maquiada

Enviadesci, enviadesci

E agora macho alfa, não tem mais pra onde fugir

Enviadesci, enviadesci

Já quebrei o meu armário, agora eu vou te destruir

Porque antes era viado

Agora eu sou travesti

(Enviadescer, Linn da Quebrada)

$\mathrm{Na}$ música apresentada acima,observa-se o processo de desvalorização do sujeito masculino e valorização do feminino em um movimento de resistência. Enviadescer é apresentado como um termo que designa o processo de tornar-se afeminado ou "viado".O termo viado foi e ainda é usado em muitos momentos com valor pejorativo, mesmo dentro da comunidade LGBTQ+, mas na música, subvertem-se essas relações de poder e instaura-se um valor positivo ao processo "enviadescer", na medida em que tal subjetividade ganha visibilidade e é assumida com certo orgulho.

Instaura-se um diálogo com o "macho discreto", retomando aqui o sujeito discutido anteriormente do "macho" ou "macho alfa". A palavra "discreto" faz referência também a uma designação comum entre os homens homossexuais que costumam fazer a distinção entre discretos e afeminados. Discretos seriam aqueles que não são assumidos ou, se são, comportam-se de maneira discreta, podem se "camuflar" dentro da sociedade heteronormativa, vivendo sua homossexualidade de forma reservada. Esse pode ser considerado um reflexo da coerçãoheteronormativa na comunidade LGBTI+. O discurso constituído nas músicas, entretanto, demonstra um movimento de enfrentamento à posição de poder do masculino e àrepresentação do homem masculino como desejado: "Que eu não tô interessada no seu grande pau ereto". Rompendo com esse padrão,observa-se a valorizaçãodo feminino: "Eu gosto mesmo é das bixas, das que são afeminada/ Das que mostram muita pele, 
rebolam, saem maquiada". Por fim é invertido o processo e o afeminado torna-se objeto de desejo, contrariando oideal de que apenas o homossexual masculino seja atraente e o feminino como o cômico: "Se tu quiser ficar comigo, boy (ha-ha-ha)/ Vai ter que enviadescer".

O processo de enviadescermostra-se como algo que vai além do tornar-se viado ou afeminado, "Mas não tem nada a ver com gostar de rola ou não/ Pode vir, cola junto as transviadas, sapatão". Trata-se de romper com os padrões construídos de gênero e tornar-se algo original. Esse, então, estaria ligado a toda a comunidade LGBTQ+ e culminaria na sua libertação das regras da normatividade.

Na última estrofe da música, retomando o diálogo com o "macho alfa", é enfatizado novamente o enfrentamento e a resistência do afeminado que se liberta das amarras e regras antes em vigor e toma o lugar de poder antes do masculino: "E agora macho alfa, não tem mais pra onde fugir/ Enviadesci, enviadesci/ Já quebrei o meu armário, agora eu vou te destruir". Omovimento de "sair do armário" é significado não só como assumir a homossexualidade, mas assumir-se como afeminado.

Circula pela sociedade a concepção de que a passividade sexual estaria ligada ao feminino, enquanto a atividade seria própria ao masculino. Apesar de questionada e problematizada, essa relação retorna nos discursos produzidos sob efeito de retomada de memórias em diversos momentos. A música Talentolida e subverte essas relações: "Nem vem com esse papo/ Feminina tu não come?/ Quem disse que linda assim/Vou querer dar meu cu pra homem?" Esse movimento continua em Coytada: "Sua bichinha safada/ Cê só quer dar pras gay bombada/ E eu sou muito afeminada". A ideia da "gay bombada" pode ser relacionadaao "macho", "macho alfa" ou "macho discreto" versus a afeminada.

Tu vem me dizer que só trepar com homem bombado

Apenas pare, querida

Vem foder com os viados

Cêsabe

Eu não sou sarada

E não faço academia

Mas arraso numa cama

Inventando pornografia

E se tu me desse bola

Eu dava, eu dava, dava

Eu dava, mas te comia

Mas eu sei que tu só goza de boyzinho glamoroso

Vem aqui me dá uma chance?

Evamo foder gostoso

Esses ocó só quer socar quando não tem ninguém mais vendo

Comigo é diferente 


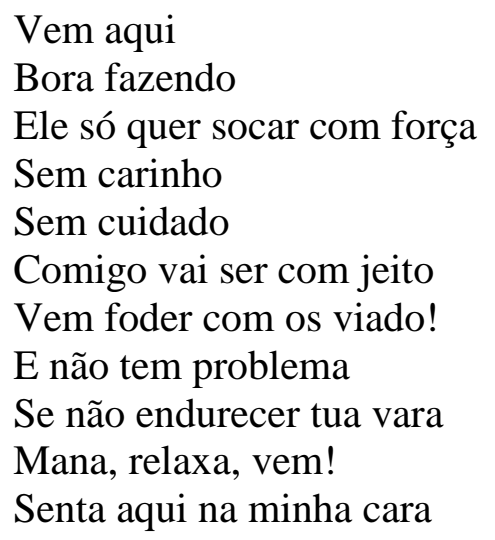

(Prostituto/Pare Querida, Linn da Quebrada)

A música Prostituto/Pare Querida põe em questão mais fortemente o enfrentamento das tradicionais regras sobre a sexualidade. Inicia-se com um diálogo no qual opõem-se: masculinidade e sexualidade:"Tu vem me dizer que só trepar com homem bombado/ Apenas pare, querida/ Vem foder com os viados", e também a ideia de que o macho seria sexualmente superior ao viado: "Cêsabe/ Eu não sou sarada/ E não faço academia/ Mas arraso numa cama/ Inventando pornografia".Invertendo a balança que viria da heteronormatividade, questiona-se a relação de o penetrado como passivo/afeminado e do que penetra como o macho/ativo. A cantora desloca essa taxomia e se coloca como afeminada/ativa/a que penetra "E se tu me desse bola/ Eu dava, eu dava, dava/ Eu dava, mas te comia”.

Observa-se uma crítica à relação sexual oculta, praticada pelo "macho discreto" que a mantêm escondida no intuito de pertencer à sociedade heteronormativa; e também à indiferença desse para com os desejos e necessidades daquele com quem se relaciona: "Esses ocó só quer socar quando não tem ninguém mais vendo/ Comigo é diferente (...) Ele só quer socar com força/ Sem carinho/ Sem cuidado/ Comigo vai ser com jeito/ Vem foder com os viado!".

Torna-se claro a força de resistência manifestada na arte de Linn da Quebrada. A partir das músicas analisadas, nota-se o jogo de forças que ocorre dentro dessa comunidade influenciando na formação das subjetividades dos indivíduos que dela fazem parte. É evidente também a necessidade que alguns pertencentes a essa comunidade veem em transgredir esse status quo e criar uma nova verdade enfrentando o machismo que ainda reflete nas relações homossexuais.

\section{Considerações Finais}


As análises das músicas aqui apresentadas mostram um movimento continuo e cíclico dentro da comunidade LGBTQ+ e do MHB. Como é possível perceber pela história do MHB, essa comunidade, desde suas origens com a primeira onda e o grupo SOMOS, se constrói pela fragmentação e divisão de seus membros, os quais se relacionam por relações de poder e resistência exercidos entre eles e deles para com os de fora da comunidade.

Poderes machistas regulam a participação e a posição em que aqueles que pertencem a essa comunidade serão colocados. Comprova-se isso com a pouca, ou nenhuma participação de grupos femininos nos primeiros momentos do MHB. Isso só mudou a partir de um momento de resistência em que surgiram os primeiros grupos lésbicos e o reconhecimento de travestis e transexuais como parte integrante dessa comunidade. A ciclicidade dessas relações nos trazem ao momento atual, em que os poderes de regulamentação heteronormativos e machistas dividem parte dessa comunidade. As relações vão além do sexo biológico e organizam sua hierarquia a partir de representações socialmente construídas dos gêneros masculino e feminino. Dessa maneira, não só lésbicas, mas também homens homossexuais afeminados, não binários, transexuais e travestis são marginalizadas socialmente. Isso ocorre tanto na sociedade heteronormativa como também na comunidade LGBTI+. Nesse sentido, o discurso produzido nas músicas de Linn surge como uma resistência, ao colocar em cheque a posição do homossexual 'macho' e dar visibilidade e enaltecer o homossexual afeminado, a 'bicha'.

\section{Referências}

BUTLER, J. Problemas de gênero: feminismo e subversão da identidade. Rio de Janeiro: Editora Civilização Brasileira, 2003.

FACCHINI, R. Movimento homossexual no Brasil: recompondo um histórico. Cad. AEL, v.10. p. 82-125. n.18/19, 2003.

FOUCAULT, M. Genealogia e poder. In . Microfísica do Poder. São Paulo: Graal, 2013a. 2013b.

Nietzsche, a genealogia e a história. In Microfísica do Poder. São Paulo: Graal, . Os intelectuais e o poder. In . Microfísica do Poder. São Paulo: Graal, 2013c. Poder-corpo. In . Microfísica do Poder. São Paulo: Graal, 2013d. 
FRY, P. Da hierarquia à igualdade: a construção histórica da homossexualidade no Brasil. In: Para inglês ver: identidade e política na cultura brasileira. Rio de Janeiro, Zahar, 1982.

JÚNIOR, A. V. Do altar para as ruas: luta, resistência e construção identitária de gays, lésbicas, bissexuais e transgêneros. Bagoas. N.02. p. 171-190. 2008.

LINN DA QUEBRADA. A lenda. Pajubá. 2017. Disponível em: $<w w w . y o u t u b e . c o m / w a t c h ? v=g 3 w-t 585 D 54>$. Acesso em 20 de nov. 2018.

. Bixa travesti.Pajubá. 2017. Disponível em: <www.youtube.com/watch?v=Qf9hXNaBWs>. Acesso em 20 de nov. 2018.

. Coytada.Pajubá. 2017. Disponível em:

<www.youtube.com/watch?v=IUq4WWJRngE>. Acesso em 20 de nov. 2018.

. Enviadescer.Pajubá. 2017. Disponível

em:<www.youtube.com/watch?v=saZywh0FuEY>. Acesso em 20 de nov. 2018.

. Prostituto/ Pare querida.Pajubá. 2017. Disponível em:

<www.youtube.com/watch?v=LB4iM9X3tB8>. Acesso em 20 de nov. 2018.

. Talento.Pajubá. 2017. Disponível

em:<www.youtube.com/watch?v=hkAHuRPGgNk>. Acesso em 20 de nov. 2018.

. Transudo.Pajubá. 2017. Disponível em:

<www.youtube.com/watch?v=OKjx_llCGUk>.Acesso em 20 de nov. 2018.

MACRAE, E. A construção da igualdade: Identidade sexual e política no Brasil da "abertura". Campinas, Ed. da Unicamp, 1990. 